\title{
Development of micro processor based electronic metering mechanism for seed - an approach
}

\author{
V.V. AWARE AND S.V. AWARE
}

\begin{abstract}
A microprocessor based electronic metering mechanism was design and developed for three row planter to meter the cowpea seeds. The previously developed mechanical metering mechanism exhibited various losses in mechanical linkages and hence proved to be less precise. The metering mechanism was based on the opto electric rotary sensing. The input was given to the micro controller in the form of electric pulses from the sensor and the switches, which defined the spacing of the seed. The performance of developed planter was tested in the laboratory. For the given input of $15 \mathrm{~cm}$, the output seed spacing obtained was $16.2 \mathrm{~cm}$.
\end{abstract}

KEY WORDS : Microprocessor, Electronic metering mechanism

How to cite this Article : Aware, V.V. and Aware S.V. (2014). Development of micro processor based electronic metering mechanism for seed - an approach. Engg. \& Tech. in India, 5 (1\&2) : 26-31. 